\title{
Influence of Gender and Leg Dominance on Q-angle Among Young Adult Nigerians
}

\author{
Jaiyesimi, A.O. and Jegede, O.O. \\ Department of Physiotherapy, College of Medicine, University of Ibadan \\ Correspondence \\ A.O. Jaiyesimi, Department of Physiotherapy, College of Medicine, University of Ibadan \\ Email: goldenbelt1@yahoo.com
}

\begin{abstract}
SUMMARY
The quadriceps femoris muscle angle (Q-angle) is a known index of knee function and patellofemoral kinetics. This study reports normal values of the Q-angle measured bilaterally in a sample of young adult Nigerians aged 17 - 30 years and the influence of leg dominance and gender on the Q-angle.

Four hundred healthy volunteers (200 males and 200 females) with no history of musculoskeletal pathology that could influence the $Q$-angle participated in the study, using the non-probability sample of convenience. The $Q$-angle was measured using a universal goniometer with the subject in the erect weight-bearing position.

Results showed that in the male subjects, the $Q$-angles were $12.30 \pm 4.0^{\circ}$ and $10.38 \pm 3.49^{\circ}$ for the right and left lower limbs respectively, while in the female subjects, the Q-angles were $17.06 \pm 3.64^{\circ}$ and $14.84 \pm$ $3.47^{\circ}$ for the right and left lower limbs respectively. Analysis revealed a significant contra-lateral difference. Generally, the right $Q$-angle was significantly higher than the left $(p<0.05)$ in both the male and female subjects. The females had significantly higher $Q$-angles than their male counterparts $(p<0.05)$. Leg dominance did not have a significant influence $(p>0.05)$, as the right $Q$-angle was higher than the left in subjects with right leg dominance as well as those with left leg dominance.

From these results, the assumption that Q-angles in the right and left limbs are equal is contending, and it is therefore recommended that measures of $Q$-angles should be documented as either right or left in the clinics as well as in research reports.
\end{abstract}

KEY WORDS: Q-angle, leg dominance, gender influence

\section{INTRODUCTION}

The quadriceps femoris muscle angle (Q-angle) is the angle of incidence of the quadriceps muscle relative to the patella. It is a very important index of patellofemoral function and dysfunction (Morris, 1993; Livingston and Spaulding, 2002; Akinbo, Alimi and Noronha, 2004; Grelsamer et al, 2005 and Sendur et al, 2005). It is described as a reflection of the force of the quadriceps muscle on the patella in the frontal plane. Drawing an imaginary line from the anterior superior iliac spine (ASIS) to the centre of the patella and from the centre of the patella to the middle of the tibial tuberosity, delineates the Q-angle (Horton and Hall, 1989 and Livingston, 1998). The acute angle thus formed is read off as the Q-angle. These landmarks have been standardized (Schulties et al, 1995). Its value, if in excess of the normal range, is taken as an indicator of possible knee pathology and may also serve as a prognostic value in the management of these conditions.

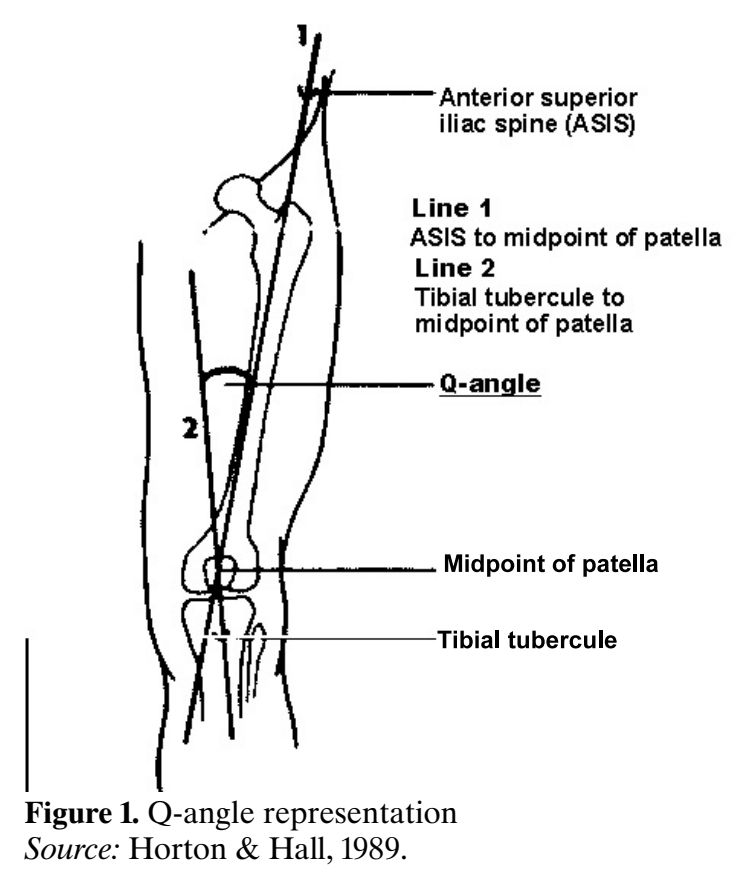

Source: Horton \& Hall, 1989. 
Important as the Q-angle is, it has been a subject of intense controversy, especially in terms of estimating values with a normal range. Any value in excess of $15^{\circ}-20^{\circ}$, however, is generally labelled as excess (Levine, 1979; Paulos et al, 1980; Huberti et al, 1984; Livingston and Mandingo, 1997). The inability to reach a definitive value for the $\mathrm{Q}$-angle can be ascribed to methodological differences in measurement and bilateral symmetry or asymmetry. Differences in subject-positioning significantly affect the values reported. Subjects are usually measured in the supine position, but this does not take into account the erect weight-bearing position (Livingston, 1998). The contractile state of the quadriceps femoris muscle is also to be taken into consideration. The subjects must be informed to relax the quadriceps muscle, as this is expected to affect the measurement.

D'amico and Rubin (1986) investigated the effects of foot orthoses on Q-angle, and concluded that subjects should be barefoot before the measurements are taken in the weight-bearing position. Most authors reported one value in their studies (Hvid, Andersen and Schmidt, 1981; Woodland and Francis, 1992; Caylor, Fites and Wovrel, 1993) assuming symmetry in both lower limbs of the subjects, but this is outrightly erroneous (Livingston, 1998). Livingstone suggested that the only reason for reporting one value should be for research purposes and not for any significant clinical extrapolation. Livingston and Mandigo (1997) reported asymmetry, with the differences ranging from $0.9^{\circ}$ in men and $1.7^{\circ}$ in women. They also reported $50 \%$ of the subjects displaying a bilateral difference of at least $4^{\circ}$ between the right and left Q- angles. One-fifth of the subject population (10 out of 50) had differences ranging from $8^{\circ}-10.3^{\circ}$. Despite overwhelming evidence indicating that young women have greater $\mathrm{Q}$-angles than their male counterparts, with differences ranging from $2.7^{\circ}$ $5.8^{\circ}$ and $3.4^{\circ}-4.9^{\circ}$. Skalley et al (1993) and Livingston and Mandigo (1997) reported no significant statistical difference in mean Q-angles between their male and female groups. The purported reason for the disparity is the wide gynaecoid pelvis of the females. The wide pelvis creates more lateral proximal reference points for the measurement and necessitates a more valgus orientation of the knee on weight-bearing to establish a mechanical axis through the hip, knee and ankle (Hvid, Andersen and Schmidt, 1981; Woodland and Francis, 1992). Shorter femurs in women may also be contributory (Horton and Hall, 1989). However, these reasons are still considered inconclusive (Livingston, 1998). There is a dearth of literature relating Q-angle to leg dominance. In fact, Akinbo, Tella and Jimo (2008) in their concluding remarks stated that all the subjects in their study were right dominant and suggested that further study may be conducted on the left dominant subjects. This study therefore sought to investigate the bilateral differences and the influence of gender and leg dominance on $\mathrm{Q}$-angle among young adult Nigerians.

\section{Methodology}

The consent of 400 (200 males and 200 females) healthy students of the University of Ibadan, Nigeria, aged 17-30 years were sought to participate in the study after due explanations. The ethical guidelines according to the Helsinki declaration were duly followed. The nonprobability sample of convenience was utilized. Inclusion criteria were as follows:

1. Subject should have no history of knee pathology.

Prospective participants were excluded based on the patella apprehension test.

2. Subject should have easily palpable landmarks, including the anterior superior iliac spine, tibial tubercle and patella margins.

\section{Materials}

The materials used include the following:

- A plastic universal goniometer to measure the Q-angle

- A bathroom scale (Hanson, Ireland) to measure the body weight

- A mobile height meter to measure the standing height

- An indelible marker to mark the anatomical landmarks

\section{Procedure}

A brief description of the procedure was given to the subjects after recording their age, gender, weight and height. Each subject, dressed in shorts and T-shirt, was decently exposed to show the landmarks. With the subject standing in the erect, weight-bearing position, the anatomical landmarks including the border of the patella, tibia tubercle and anterior superior iliac spine (ASIS) were palpated and the centre of the patella marked by an indelible marker. The axis of the goniometer was placed on the midpoint of the patella, its stationary arm on the ASIS while the movable arm was aligned to the tibial tubercle. The angle formed was read off as the Q-angle. The quadriceps muscle was kept relaxed (without voluntary quadriceps contraction) throughout the measurement and the subject was barefooted. All measurements were taken by the same investigator. An excellent intertester reliability 
(ICC, $\mathrm{r}=0.80)$ has been reported for Q-angle measurement (Shrout et al, 1979; Fleiss, 1986).

The leg dominance of the subjects was noted by appropriate questioning and the subjects were assigned to 4 groups:

$\begin{array}{ll}\text { Group I: } & \text { Right Leg Dominant Males (RDM) } \\ \text { Group II: } & \text { Left Leg Dominant Males (LDM) } \\ \text { Group III: } & \text { Right Leg Dominant Females (RDF) } \\ \text { Group IV: } & \text { Left Leg Dominant Females (LDF) }\end{array}$

\section{Analysis of Data}

The subjects' age, weight, height, right Q-angle (RQA) and left Q-angle (LQA) were recorded as the mean and standard deviation. The independent t-test was used to compare the Q-angles in the male and female groups. The paired t-test was used to test for bilateral symmetry within subject Q-angle difference. The 2 X 2 analysis of variance (ANOVA) procedure with gender and limb (right, left) as the independent variables, was used to compare the physical characteristics of the subjects. Where ANOVA indicated significant across-group difference, the Duncan's Multiple Range test was used for post-hoc analysis to see which pair(s) of groups differed significantly. The level of significance was fixed at 0.05 .

\section{RESULTS}

The subjects in the study were aged 17-30 years, weighed between $39.0-83.0 \mathrm{~kg}$ and were $1.54-2.01 \mathrm{~m}$ tall. The mean and standard deviation of the physical characteristics of the subjects are recorded in table 1 . The male subjects were significantly $(\mathrm{p}<0.05)$ heavier and taller than the female subjects.

Table 2 shows the mean Q-angles recorded for each of the four groups. The paired t-test was used to compare the right and left Q-angles (RQA and LQA) in each group. All the male subjects (right leg dominant \{Group I\} and left leg dominant \{Group II $\}$ ) had significantly higher RQA $(\mathrm{P}<0.05)$. Among the females, the right leg dominant subjects $\{$ Group III $\}$ had significantly higher RQA $(\mathrm{P}<$ $0.05)$, but the difference was not significant $(\mathrm{P}>0.05)$ in the left leg dominant group $\{$ Group IV $\}$. The average difference between the RQA and LQA was $2.04 \pm 3.16^{\circ}$ for all the subjects.

Table 3 also presents the mean differences for the male and female subjects. Seventy-four (18.5\%) of the subjects had higher LQA, while $38(9.5 \%)$ had equal RQA and LQA. Majority of them $(288,72.0 \%)$ had higher RQA. Among those who had higher LQA, the maximum difference was $8.00^{\circ}$, while among those with higher RQA, a difference of up to $16.00^{\circ}$ was observed (table 3 ).

The independent t-test was used to compare the Qangles between the male and female subjects. The result summarized in table 4 shows that the female subjects had significantly higher $\mathrm{Q}$-angles than their male counterparts $(\mathrm{p}<0.001)$ in both legs.

Table 1. Physical characteristics of subjects

\begin{tabular}{|c|c|c|c|c|c|c|c|}
\hline & & \multicolumn{2}{|c|}{ Male } & \multicolumn{2}{|c|}{ Female } & \multirow[t]{2}{*}{ F- ratio } & \multirow[t]{2}{*}{$\mathrm{P}$-value } \\
\hline & & $\begin{array}{l}\text { Right Leg } \\
\text { Dominant } \\
(\mathrm{N}=189)\end{array}$ & $\begin{array}{c}\text { Left Leg } \\
\text { Dominant } \\
(\mathrm{N}=11)\end{array}$ & $\begin{array}{c}\text { Right Leg } \\
\text { Dominant } \\
(\mathrm{N}=194)\end{array}$ & $\begin{array}{c}\text { Left Leg } \\
\text { Dominant } \\
(\mathrm{N}=6)\end{array}$ & & \\
\hline Age & $\mathrm{X}$ & 22.94 & 23.36 & 22.14 & 22.00 & 3.744 & 0.011 \\
\hline (Yrs) & S.D. & 2.75 & 2.42 & 2.21 & 2.00 & & \\
\hline \multirow{2}{*}{$\begin{array}{l}\text { Weight } \\
(\mathrm{Kg})\end{array}$} & $\mathrm{X}$ & 62.74 & $64 \overline{14}$ & 57.66 & 59.00 & 14.125 & 0 \\
\hline & S.D. & 7.42 & 5.66 & 8.27 & 12.95 & & \\
\hline \multirow{2}{*}{$\begin{array}{l}\text { Height } \\
(\mathrm{cm})\end{array}$} & $\mathrm{X}$ & 1.74 & 1.71 & 1.63 & 1.63 & 92.043 & 0 \\
\hline & S.D. & 0.06 & 0.07 & 0.06 & 0.07 & & \\
\hline
\end{tabular}

Horizontal lines join pairs of values that are significantly different $\mathrm{p}<0.05$ 
Influence of Gender and Leg Dominance on Q-angle among Young Adult Nigerians

Table 2. Q-angle measures and paired t-test to compare the within-subject bilateral symmetry

\begin{tabular}{|c|c|c|c|c|c|c|c|c|}
\hline & & \multicolumn{2}{|c|}{ Male } & \multicolumn{2}{|c|}{ Female } & \multicolumn{2}{|c|}{ Male \& Female } & \multirow{2}{*}{$\begin{array}{l}\text { All Subjects } \\
(\mathrm{N}=400)\end{array}$} \\
\hline & & $\begin{array}{l}\text { Right leg } \\
\text { Dominant } \\
(\mathrm{N}=189)\end{array}$ & $\begin{array}{l}\text { Left leg } \\
\text { Dominant } \\
(\mathrm{N}=11)\end{array}$ & $\begin{array}{l}\text { Right leg } \\
\text { Dominant } \\
(\mathrm{N}=194)\end{array}$ & $\begin{array}{l}\text { Left leg } \\
\text { Dominant } \\
(\mathrm{N}=6)\end{array}$ & $\begin{array}{l}\text { Right leg } \\
\text { Dominant } \\
(\mathrm{N}=383)\end{array}$ & $\begin{array}{l}\text { Left leg } \\
\text { Dominant } \\
(\mathrm{N}=17)\end{array}$ & \\
\hline \multirow[t]{2}{*}{ Right } & $\mathrm{X}$ & 12.164 & 12.818 & 17.167 & 14.417 & 14.698 & 13.382 & 14.640 \\
\hline & S.D. & 4.006 & 3.133 & 3.633 & 2.905 & 4.565 & 3.065 & 4.520 \\
\hline \multirow[t]{2}{*}{ Left } & $\mathrm{x}$ & 62.740 & 64.140 & 57.660 & 59.000 & 12.655 & 11.529 & 12.610 \\
\hline & S.D. & 7.420 & 5.660 & 8.270 & 12.950 & 4.124 & 4.252 & 4.130 \\
\hline \multicolumn{2}{|c|}{ Calculated t } & 7.755 & 2.456 & 10.235 & 0.139 & 12.704 & 2.012 & 12.86 \\
\hline \multicolumn{2}{|c|}{ P-value } & $0.000^{*}$ & $0.034^{*}$ & $0.000^{*}$ & 0.895 & $0.000^{*}$ & 0.051 & $0.000^{*}$ \\
\hline
\end{tabular}

* Indicates significant difference $\mathrm{p}<0.05$

Table 3. Differences between the right and left Q-angles (in degrees)

\begin{tabular}{lrrrrrrrr}
\hline & \multicolumn{3}{c}{ Male } & & Female & All \\
\cline { 2 - 8 } & RDM & LDM & All & RDF & LDF & All & \\
& $(\mathrm{N}=189)$ & $(\mathrm{N}=11)$ & $(\mathrm{N}=200)$ & $(\mathrm{N}=194)$ & $(\mathrm{N}=6)$ & $(\mathrm{N}=200)$ & $(\mathrm{N}=400)$ \\
\hline Minimum & -8.00 & -2.00 & -8.00 & -6.00 & -3.00 & -6.00 & -8.000 \\
Maximum & 13.00 & 10.50 & 13.00 & 16.00 & 4.00 & 16.00 & 16.000 \\
Mean & 1.77 & 2.77 & 1.82 & 2.31 & 0.17 & 2.248 & 2.035 \\
S. D. & 3.17 & 3.74 & 3.17 & 3.15 & 2.93 & 3.16 & 3.164 \\
\hline
\end{tabular}

$\mathrm{DRL}=\mathrm{RQA}-\mathrm{LQA} \quad$ (negative sign denotes a higher LQA than RQA)

$$
\text { where: }
$$

DRL - Bilateral difference in Q-angle

RDM - Right leg dominant subjects

RQA - Right Q-angle

LDM - Left leg dominant subjects

LQA - Left Q-angle

Table 4. Independent t-test to compare Q-angles in male and female subjects

\begin{tabular}{llcccc}
\hline & & $\begin{array}{l}\text { Male } \\
(\mathrm{N}=200)\end{array}$ & $\begin{array}{c}\text { Female } \\
(\mathrm{N}=200)\end{array}$ & Calculated t & P-value \\
& & & & \\
Right & $\mathrm{X}$ & 12.200 & 17.085 & 12.847 & $0.000^{*}$ \\
& S.D. & 3.960 & 3.638 & & \\
\multirow{2}{*}{ Left } & $\mathrm{X}$ & 10.378 & 14.837 & 12.815 & $0.000^{*}$ \\
& S.D. & 3.490 & 3.467 & & \\
\hline
\end{tabular}

* Indicates significant gender difference $\mathrm{p}<0.001$

The subjects were rearranged to test for the influence of leg dominance, all the right leg dominant subjects (Groups I and III, $\mathrm{n}=383$ ) and left leg dominant subjects (Groups II and IV, $\mathrm{n}=17$ ) were pooled together. For each of these larger groups, the right and left Q-angles were compared for symmetry or asymmetry using the paired $t$ test. The results are summarized in table 2 . The right leg dominant subjects had significantly higher RQA ( $\mathrm{p}<$ $0.001)$, but the difference was not significant $(\mathrm{p}>0.05)$ among the left leg dominant subjects.

\section{DISCUSSION}

The study established that the average Q- angle for the right and left limbs in the male population are $12.20 \pm$ $3.96^{\circ}$ and $10.38 \pm 3.49^{\circ}$, respectively. For the female population, the right and left $\mathrm{Q}$-angles are $17.09 \pm 3.64^{\circ}$ and $14.84 \pm 3.47^{\circ}$. It is difficult to compare the results of this study with previous Nigerian studies on Q-angle, because most of them reported one value only. There are also differences in methodologies, in that they all measured the Q-angle using the flexiometer, while this study used the goniometer, which is more popular among medical practitioners. The only Nigerian study that employed a similar methodology (Akinbo et al, 2008) reported values close to the ones observed in this study. For their asymptomatic subjects (all male), they reported RQA and LQA of $12.88 \pm 1.30^{\circ}$ and $15.70 \pm 1.72^{\circ}$, respectively. The values obtained in this study are higher than those reported by Livingston and Mandigo (1997). They reported for their male population $(\mathrm{N}=50) \mathrm{RQA}$ and LQA of $9.5 \pm 4.6^{\circ}$ and $10.4 \pm 5.7^{\circ}$, respectively; for the female population $(\mathrm{N}$ $=50)$, RQA and LQA of $10.5 \pm 4.2^{\circ}$ and $12.2 \pm 5.2^{\circ}$. The values are also higher than those reported by Byl and 
Livingston (1999). They reported for their male population $(\mathrm{N}=16), \mathrm{RQA}$ and LQA of $6.3^{\circ}$ and $5.9^{\circ}$, respectively; for the female population $(\mathrm{N}=18), \mathrm{RQA}$ and LQA of $10.1^{\circ}$ and $9.7^{\circ}$. The differences between these values and those of the present study may therefore be racial.

\section{Bilateral Asymmetry}

Across the four groups, with the exception of the left leg dominant female group, the RQA was significantly higher than the LQA $(p<0.05)$. This is consistent with the results of Hahn and Foldspan (1997), but does not correspond to that Livingston and Mandigo (1997) and Akinbo et al (2008), who reported higher LQA than RQA. The average difference of 1.82 between the RQA and LQA for the male subjects and $2.25^{\circ}$ for the female subjects obtained in this study, though higher than $0.9^{\circ}$ in men and $1.7^{\circ}$ in women reported by Livingston and Mandigo (1997), shows a similar trend of greater asymmetry in the female than in the male Q-angles.

\section{Gender Effect}

Significantly higher Q-angles were recorded in both the RQA and LQA of the females. This is consistent with previous studies (Woodland, 1992; Livingston, 1998). The initially accepted, though unproven explanation for the greater Q-angles in women, is that a woman has a wider pelvis. This may no longer be a valid explanation considering the report of Grelsamer et al (2005). These researchers opined that because of the long distance between the pelvis and patella, relative to the distance from the patella to the tibial tuberosity, large changes in the position of the anterior superioriliac spine are necessary to effect significant changes in the Q-angle. In their study of 69 subjects, Grelsamer et al did not find such large differences in the position of the anterior superior iliac spine, and found a mean difference of only $2.3^{\circ}$ between the Q-angles of men and women. Furthermore, they found that men and women of equal heights demonstrated similar Q-angles, with taller people having slightly smaller Qangles. It was concluded that the slight difference in $\mathrm{Q}$ angles between men and women can be explained by the fact that men tend to be taller.

\section{Leg Dominance Effect}

The results of this study suggest that leg dominance does not significantly influence the $\mathrm{Q}$-angle. There were no previous studies to compare this finding with.

\section{CONCLUSION}

From the foregoing, we conclude that the right and left Qangles are not equal in the same individual and are higher in women. No significant relationships were established between Q-angle and leg dominance, but this is inconclusive. We recommend that in recording $\mathrm{Q}$-angle measurements, both limbs should be measured.

\section{References}

Akinbo, S.R.A., Alimi, N.O. and Noronha, C.C. (2004) Relationship between bilateral knee joint osteoarthritis and the Q-angle. South Africa Journal of Physiotherapy 60, pp. 2629.

Akinbo, S.R.A., Tella, B.A., Jimo, O.O. (2008) Comparison of bilateral quadriceps angle in asymptomatic and symptomatic males with unilateral anterior knee pain. The International Journal of Pain, Symptom Control and Palliative Care 6(1).

Byl, T. and Livingston, L.A. (1999) Bilateral imbalances in Qangles and quadriceps peak torque measurements.

http://www.asbweb.org/conferences/1990s/1999/ ACROBAT/014.PDF.

Caylor, D., Fites, R. and Wovrel, T.W. (1993) The relationship between quadriceps angle and anterior knee pain syndrome. Journal of Orthopaedic and Sports Physical Therapy 17(1), pp.11-16.

D'amico, J.C. and Rubin, M. (1986) The influence of foot orthoses on the quadriceps angle. Journal of American Pediatric Association 76(6), pp.337-340.

Grelsamer, R.P. (2005) Men and women have similar Q-angles: A clinical and trigonometric evaluation. Journal of Bone and Joint Surgery 87(11), pp.1498 -1501.

Hahn, T. and Foldspan, A. (1997) The Q-angle and sport. Scandinavian Journal of Medicine Science and Sports 7(1), pp. 43- 48.

Horton, M.G. and Hall, T.L. (1989) Quadriceps femoris muscle angle: Normal values and relationship with gender and selected skeletal measures. Physical Therapy 69(11), pp.897901.

Huberti, H.H. and Hayes, W.C. (1984) Patellofemoral contact pressures: The influence of Q-angle and tendofemoral contact. Journal of Bone and Joint Surgery 66A(5), pp.715724.

Hvid, I., Andersen, L.I. and Schmidt, H. (1981) Chondromalacia patellae: The relation to abnormal patellofemoral joint mechanics. Acta Orthopedic Scandinavia 52, pp. 661-666.

Levine, J. (1979) Chondromalacia patellae. The Physician and Sports Medicine 7(8), pp. 41-49.

Livingston, L.A. (1998) Q-angle: A review of literature.Journal of Orthopaedics and Sports Physical Therapy 28(2), pp. 105-109. 
Livingston, L.A. and Mandigo, J.L. (1997) Bilateral within-subject Q-angle asymmetry in young adult females and males. Biomedical Science Instrumentation 33, pp. 112-117.

Livingston, L.A., Spaulding, S.J. (2002) Measurement of the quadriceps angle using standardized foot positions. Journal of Athletic Training 37, pp.252-255

Morris, C.M. (1993) Sports injuries: Diagnosis and management for physiotherapists. Oxford. Butterworth-Heinemann Ltd.

Paulos, L., Rusche, K., Johnson, C. and Noyes, F.R. (1980) Patella malalignment: A treatment rationale. Physical Therapy 66A(5), pp. 715-724.

Schulthies, S.S., Francis, R.S., Fisher, A.G. and Van De Graff, K.M. (1995) Does the Q-angle reflect the force on the patella in the frontal plane? Physical Therapy 75(1), pp. 3036.
Sendur, O., Gurer, G., Yildirim, T., Ozturk, E., Aydeniz, A. (2005) Relationship of Q-angle and joint hypermobility and $\mathrm{Q}$-angle values in different positions. Clinical Rheumatology 25, pp. 304-308.

Skalley, T.C., Terry, G.C. and Teitge, R.A. (1993) The quantitative measurement of normal passive medial and lateral patella motion limits. American Journal of Sports Medicine 21(5), pp. 728-732.

Woodland, L.H. and Francis, R.S. (1992) Parameters and comparisons of the quadriceps angle of college-aged men and women in the supine and standing positions. American Journal of Sports Medicine 20(2), pp. 208-211. 